Gisel e Pei xoto Barbosa 1,2

Karen Giffin 1

Antonia Angulo-Tuesta 1

Andrea de Souza Gama 1

Dóra Chor 3

Eleonora D'Orsi 1

Ana Cristina Gonçal ves Vaz dos Reis 1

\section{Parto cesáreo: quem o deseja? Em quais circunstâncias?}

\author{
Cesarean sections: who wants \\ them and under what circumstances?
}

1 Núcleo de Gênero e Saúde, Departamento de Ciências Sociais, Escola Nacional de Saúde Pública, Fundação Oswal do Cruz. Rua Leopoldo Bulhões 1480, Rio de Janeiro, RJ 21041-210, Brasil. gpbarbosa@zipmail.com.br 2 Programa de Assistência Integral à Saúde da Mulher, Criança e Adolescente, Secretaria de Estado de Saúde do Rio de Janeiro. Rua México 128, Rio de Janeiro, RJ 20031-142, Brasil. 3 Departamento de Epidemiologia e Métodos Quantitativos em Saúde, Escola Nacional de Saúde Pública, Fundação Oswaldo Cruz. Rua Leopoldo Bulhões 1480, Rio de Janeiro, RJ 21041-210, Brasil.
Abstract Brazil has extremely high cesarean rates. Among related factors, it has been suggested that a "culture of cesarean childbirth" (or a preference for this type of del ivery) exi sts among Brazilian women. Our study investigates this notion. Data were collected from September 1998 to March 1999 in two maternity hospitals in Rio de Janeiro Interviews were conducted and hospital records analyzed for a random representative sample of 909 women who had just given birth ( 454 vaginal deliveries and 455 cesareans). In the interviews, when asked if they had wanted to have a cesarean, $75.5 \%$ replied in the negative, thus indicating that these women cannot be consi dered as adhering to a "culture of cesarean sections" The main complaints against cesareans were: slower and more difficult recovery (39.2\%) and greater pain and suffering (26.8\%). However, $17 \%$ of the sample had at some point requested a cesarean, $75 \%$ of whom during labor. Analysis revealed that the request for a cesarean section is directly proportional to time between admission to the hospital and delivery. This suggests that (in addition to being the usual means of access to tubal ligation) the actual circumstances of birthing are important factors in Brazilian women's requests for cesarean sections.

Key words Cesarean Section; Perinatal Care; Reproductive Health

Resumo O Brasil apresenta altos índices de cesáreas. Este estudo investigou a existência de uma "cultura de cesárea", ou preferência por este tipo de parto, através de uma amostra de 909 puérperas (454 vaginais e 455 cesáreos) em duas materni dades do Município do Rio de Janeiro, onde entrevistas e revisão de prontuários foram realizados entre setembro de 1998 e março de 1999. Perguntou-se às mulheres se queriam que seu parto fosse cesáreo e a mai oria absol uta (75,5\%) respondeu "não", as razões princi pais sendo: "recuperação mais difícil e lenta no parto cesáreo" (39,2\%) e "dor e sofrimento maior depois da cesárea" (26,8\%). Apenas 17\% das mul heres sol i ci taram cesárea e, destas, cerca de $75 \%$ o fizeram durante o trabal ho de parto/parto. Análise mostrou que quanto maior o interval o de tempo entre a admissão no hospital e o parto, mais freqü ente é a solicitação. A maioria das mulheres, nas maternidades estudadas, não quer e não pede cesárea; ou seja, não existe uma 'cultura' feminina que valorize a cesárea como preferência. Além do desejo da laqueadura, as circunstânci as concretas da assi stência no pré-parto/parto parecem influenciar no pedido da mulher.

Palavras-chave Cesárea; Assistência Perinatal; Saúde Reprodutiva 


\section{Intro dução}

A magnitude da questão cesárea

A cesárea é um procedimento cirúrgico originalmente desenvolvido para salvar a vida da mãe e/ ou da criança, quando ocorrem complicações durante a gravidez ou o parto. É, portanto, um recurso utilizável quando surge algum tipo de risco para a mãe, o bebê ou ambos, durante a evolução da gravidez e/ ou do parto. Como todo procedimento cirúrgico, a cesárea não é isenta de riscos, estando associada, no Brasil e em outros países, a maior morbimortalidade materna e infantil, quando comparada ao parto vaginal (Faundes \& Cecatti, 1991; McClain, 1990; Miller, 1988). A escolha de qualquer intervenção médica, em termos éticos, deve basear-se no balanço entre riscos e benefícios. No Brasil e em outros países, no entanto, a cesárea tem sido abusivamente utilizada, sem benefícios para as mulheres e recémnatos (Shearer, 1993).

Nos últimos 30 anos tem sido observado um aumento progressivo das taxas de cesárea em quase todos os países, embora não de forma homogênea. A magnitude dessa tendência foi maior nos Estados Unidos, no Canadá, em Porto Rico e no Brasil (Sakala, 1993). Esses países ultrapassaram, na década de 80, o índice de $15 \%$, considerado pela Organização Mundial de Saúde (OMS) como a taxa máxima aceitável de cesárea para qualquer região (OMS, 1996). A maioria dos países europeus, nessa mesma época, apresentou taxas entre $10 \%$ e $14 \%$, com exceção da Holanda - onde o sistema de atenção ao parto privilegia o atendimento domiciliar e conta com a participação efetiva de parteiras -, que apresentou taxas próximas a 7\%. (Sakala, 1993). É importante também destacar que as taxas de cesárea podem variar dentro de um mesmo país.

Dados nacionais recentes (BEM FAM, 1997) confirmam a tendência de crescimento desse tipo de parto, que alcançou $36 \%$ no Brasil, com taxas maiores em São Paulo (52\%) e na Região Centro-Oeste ( $49 \%)$, sendo as menores taxas nas Regiões Nordeste (20\%) e Norte (25\%). Observa-se, ainda, que o parto cesáreo é mais freqüente na região urbana $(41,8 \%)$ do que na região rural $(20,1 \%)$ e mostra-se também fortemente associado ao grau de instrução da muIher, aumentando progressivamente com o número de anos de estudo (BEM FAM, 1997). Existe, portanto, grande variabilidade das taxas de cesárea segundo as diversas unidades de análise: estados, municípios, bairros ou hospitais. No município do Rio de Janeiro, em 1995, por exemplo, a taxa de cesárea foi de $46 \%$. Nos hospitais com mais de 1.000 nascimentos/ano, essa taxa variou de $9,8 \%$ a $84,5 \%$ (Campos \& Carvalho, 2000).

O uso iatrogênico da cesárea é indicado pelo fato de ser esta mais freqüente em hospitais privados e em regiões de maior renda, cujas gestantes estão em melhores condições sociais e de saúde, apresentando, em princípio, menor risco gestacional (Rattner, 1996).

Ao longo das últimas décadas muito se tem debatido sobre a assistência ao parto. Diversas análises realizadas, que retratam a complexidade de fatores que cercam o parto (e sua assistência), têm suscitado uma série de questões, que envolvem desde a qualidade da atenção obstétrica até a constituição do significado da experiência do nascimento para nós, muIheres e homens envolvidos na reprodução.

No Brasil, a assistência ao parto deve ser compreendida no contexto de um conjunto complexo de fatores característicos da atenção à saúde reprodutiva, que inclui, além de altos índices de esterilização e partos cirúrgicos, a baixa qualidade da atenção obstétrica, reflexo da precariedade do pré-natal, das condições desumanas de assistência ao parto e da peregrinação de parturientes em busca de leitos hospitalares, se quisermos destacar apenas alguns elementos (Berquó, 1999; Diniz, 1996; Silver, 1999; Valladares, 1999).

Entre os fatores que influenciam a opção por um parto cesáreo têm sido relatados: (a) a organização da atenção obstétrica, pautada pela conveniência de uma intervenção programada e pela insegurança do médico, decorrente de treinamento insuficiente na gama de variações que ocorrem durante o desenrolar de um parto normal; (b) fatores institucionais ligados à forma de pagamento e à exclusão do pagamento de anestesia peridural para partos vaginais pelo Sistema Ú nico de Saúde (SUS), situação já revista pelo Ministério da Saúde, mas não modificada em todos os hospitais; (c) a esterilização cirúrgica, realizada freqüentemente durante cesáreas eletivas; e (d) fatores socioculturais, que levariam à preferência, por parte das mulheres e dos profissionais de saúde, por um parto cirúrgico, tais como: medo da dor no parto normal, medo de lesões na anatomia e fisiologia da vagina e a crença de que o parto vaginal é mais arriscado do que uma cesárea, sendo esta última considerada a forma mais "moderna" de se ter filhos (Faundes \& Cecatti, 1991; Rattner, 1996).

A partir de tais considerações, tem sido sugerida a existência de uma "cultura da cesárea" entre as mulheres brasileiras, ou seja, uma pre- 
ferência pelo parto cirúrgico, considerado superior ao parto vaginal.

Uma visão da questão a partir de uma perspectiva de gênero

Maternidade, gravidez e parto despontam como assuntos caros no ressurgimento do movimento feminista nos anos 60, que identificou a tradução social da função reprodutora como um ponto nevrál gico sobre o qual se assenta a opressão feminina. Dessa perspectiva, elaborou-se uma crítica à compreensão naturalizada da reprodução e da sexualidade, tratadas como dimensões biológicas da esfera privada da vida dos indivíduos, como se nessa arena não se inscrevessem relações de poder, hierarquia e violência. Para o feminismo, as questões relativas à reprodução são colocadas no plano das relações de poder e da luta política pela autodeterminação sobre o corpo e a sexualidade (Ávila, 1993; Giffin, 1991).

Historicamente, o parto se constituiu em uma arena de intensa luta de poder entre as mulheres e a ordem médica, pelo controle sobre o corpo, a sexualidade e a emoção (ver, por exemplo, Brenes, 1991). O processo histórico de medicalização do corpo feminino traduz de modo exemplar a idéia de que existe uma natureza biológica determinante da condição feminina. É justamente por meio dessa concepção que a medicina construiu o discurso legitimado sobre o corpo das mulheres e sobre a reprodução (Vieira, 1999). A partir dessa óptica, o fenômeno moderno da medicalização do nascimento é apontado como mais uma - e fundamental - instância de expressão do poder masculino.

A crítica à assistência ao parto se insere no questionamento mais amplo que as mulheres fazem aos serviços de saúde, e parte da proposição feminista de que a situação de subordinação aí experimentada pelas mulheres e expressa na medicalização do corpo feminino é socialmente determinada, e não uma decorrência natural de suas características biológicas (Diniz, 1996).

A reflexão feminista problematizou a patologização da reprodução e a maneira como as práticas médicas definem seu objeto de trabaIho, e questionou as bases históricas e políticas da concepção do feminino como "fisiologicamente patológico". A patologização do parto, articulada à construção médico-científica do feminino como "normalmente defeituoso" e dependente da tutela médico-cirúrgica, orienta-se no século 20 por um modelo de assistência ao parto como evento de risco. A tecnologia médica se apresenta, nesse sentido, como uma resposta necessária para o controle desse risco. Levada ao extremo, essa lógica passa a justificar a utilização corriqueira da tecnologia médica nos nascimentos, a despeito de qualquer indicação clínica mais precisa (Scavone, 1992).

No caso do Brasil, o trabalho de Mello-eSouza (1994) visa contribuir para a compreensão do processo de legitimação social do parto cesáreo, tanto pelos médicos como pelas pacientes, como um tipo de parto seguro, indoIor, moderno e ideal para qualquer grávida. A autora busca elucidar a forma pela qual valores culturais referentes à dor do parto vaginal, à imagem corporal feminina e ao fascínio pela tecnologia foram manipulados pela biomedicina a fim de acomodar essa prática dentro da orientação geral da medicina ocidental em relação à beneficência ("poupar a mulher da dor"). Assim, o medo da dor passa a ser rotulado de "falta de preparo psicológico para o trabalho de parto", transformando-se em justificativa médica para a cesárea. Embora não haja fundamentação empírica para tal, a idéia de dano rotineiro ao períneo pelo parto vaginal interferindo com qualidades estéticas do corpo e com o potencial sexual feminino, valores entendidos como centrais à imagem corporal e à identidade feminina entre as mulheres brasileiras de estrato social superior - passa a justificar a cesárea como "medicina preventiva".

Mello-e-Souza argumenta que o princípio do direito da mulher ao poder e controle sobre o próprio corpo, bandeira do feminismo dos anos 60, foi apropriado pelos médicos para justificar a prática de cesáreas desnecessárias. Nesse processo, tais intervenções passam a ser denominadas "cesárea a pedido" ou "cesárea eletiva", insinuando que a "cultura da cesárea" reflete um desejo feminino (Mello-e-Souza, 1994). Conforme essa interpretação, é o desejo feminino que determina o tipo de parto, e não o poder de promoção, legitimação e divulgação dos médicos.

Nesse caminho, tratar a maternidade, a gravidez e o parto não como fenômenos meramente naturais ou fisiológicos mas fundamentalmente como experiências socialmente construídas permite compreender a complexa dinâmica de construção social da parturição, suas técnicas de assistência, seus cenários e os principais atores envolvidos. Uma abordagem multidimensional permite, então, analisar o fenômeno da parturição como um processo fisiológico que é contextualizado socialmente por um sistema complexo de valores e que envolve interações entre indivíduos, grupos sociais e instituições (maternidades) com poder 
diferenciado na definição dessas relações. Devemos, portanto, ver o parto e, especificamente, as indicações de parto cesáreo para além das questões clínicas.

\section{Uma cultura da cesárea?}

Dados recentes mostram que, na opinião dos médicos, a maioria das mulheres dá preferência ao parto cesáreo. O relatório da Pesquisa sobre Saúde Reprodutiva e Práticas Obstétricas no Brasil (Núcleo de Estudos de População, 1996) reportou que $89 \%$ dos médicos entrevistados em São Paulo achavam que as mulheres preferiam o parto cirúrgico, assinalando como razões mais importantes dessa preferência o medo do parto vaginal (65\%), a possibilidade de laqueadura (11\%) e o não-pagamento pelo SUS da anestesia para o parto vaginal (8\%). No mesmo relatório, médicos do Rio Grande do Sul também apontaram como razões para explicar a "preferência" por partos cesáreos o medo do parto vaginal $(67,3 \%)$ e a possibilidade de obter ligadura por meio de cesarianas (11,9\%).

Por outro lado, Hopkins (2000) realizou um estudo nas cidades de Porto Alegre (Rio Grande do Sul) e Natal (Rio Grande do Norte), no período de agosto de 1995 a maio de 1996, cujos resultados demonstram que as mulheres não buscam o parto cesáreo: a maioria das primíparas referiu preferir o parto vaginal. Entre as que tiveram filho por parto cesáreo, cerca de $75 \%$ (maternidade privada) e $80 \%$ (maternidade pública) afirmaram que não queriam que seu parto tivesse sido cesáreo.

Além disso, Hopkins cita estudo desenvolvido em Brasília, com mulheres de média e alta renda, que demonstra o fato de as pacientes, pelo menos no início da gestação, desejarem um parto vaginal (Carranza, 1994, apud Hopkins, 2000). A mesma autora faz referência ao trabalho de Freitas, realizado no Sul do Brasil, que mostrou que apenas uma minoria das muIheres requisita a cesárea durante o trabal ho de parto. Nesse estudo, os obstetras raramente se colocaram como responsáveis pelas al tas taxas de cesárea e, quando o fizeram, dividiram a responsabilidade com a organização dos serviços de saúde (Freitas, s.d., apud Hopkins, 2000).

Potter et al. (2001) apresentam mais recentemente um estudo prospectivo realizado em quatro capitais brasileiras (Porto Alegre, Belo Horizonte, Natal e São Paulo), no período de abril de 1998 a junho de 1999, com mulheres atendidas nos setores público e privado em três momentos do ciclo gravídico-puerperal (no início da gravidez, a um mês do parto e com um mês de pós-parto). Os autores mostram que, apesar das diferenças existentes nas taxas de cesárea entre o setor público e o privado, a preferência da maioria das mulheres ( $70 \%$ a $80 \%$ ) antes do parto era pelo parto vaginal.

Esses estudos não apóiam a idéia de uma preferência feminina pelo parto cesáreo. O presente estudo é uma tentativa de avançar na investigação da "cultura da cesárea" a partir da visão de um grupo de parturientes. Nesta análise, indagamos se pedir uma intervenção cirúrgica é o mesmo que achar o parto cesárea superior. Se as mulheres o solicitam, em que contexto e por que o fazem? Esse pedido pode ser relacionado às condições do atendimento prestado às mulheres nos serviços de saúde, ao desejo de laqueadura ou significa a noção de que o parto cesáreo é a melhor opção?

\section{Métodos}

Os dados foram coletados entre setembro de 1998 e março de 1999, em duas maternidades do município do Rio de Janeiro, sendo uma pública e outra conveniada com o SUS. Foram estudadas 909 puérperas: 461 na maternidade pública (230 partos vaginais e 231 cesáreas) e 448 na maternidade conveniada (224 partos vaginais e 224 cesáreas), sendo esta uma amostra representativa das mulheres que pariram nessas maternidades no período do estudo. Para o cálculo do tamanho da amostra foi utilizado o programa Epi Info (módulo Statcalc, tamanho da amostra e poder, estudo de casocontrole não pareado). Foi considerado um erro a igual a $5 \%$ e um poder (1-b) igual a $80 \%$. Utilizou-se a variável estado da bolsa d'água na admissão (íntegra ou rota) como variável de exposição para o cálculo de tamanho de amostra. As mulheres foram selecionadas segundo a data do parto, utilizando-se o registro da sala de parto dos hospitais. Os dados foram coletados por meio de questionários e pela revisão dos prontuários médicos após a alta das pacientes. A aplicação do questionário foi realizada nas enfermarias dos hospitais, estando as puérperas com 24 a 72 horas de pós-parto.

O questionário e a revisão dos prontuários abordaram antecedentes obstétricos, dados da gestação atual e do pré-natal, de acesso ao hospital, internação, pré-parto, parto e puerpério, sobre a condição do recém-nascido, aspectos sócio-demográficos da mulher e opiniões da mulher sobre o parto cesáreo. A análise dos dados quantitativos foi feita utilizando o pacote estatístico SPSS para Windows.

Com o objetivo de investigar se havia preferência pelo parto cesáreo, foram feitas as per- 
guntas abaixo para as 909 mulheres nas duas maternidades:

- Você queria que seu parto fosse cesáreo? Por quê?

- Em algum momento você pediu para fazer cesárea? Em caso de resposta afirmativa, em que momento?

- Vocêligou as trompas?

Além disso, foram realizadas entrevistas semi-estruturadas em profundidade com uma subamostra de 24 puérperas, 12 em cada maternidade, todas multíparas que haviam experimentado os dois de tipo de parto (vaginal e cesáreo). As entrevistas foram gravadas, transcritas e posteriormente analisadas por tema. Entre outras questões, foram abordadas as percepções quanto ao parto cirúrgico, analisadas a partir de categorias empíricas estabelecidas, neste caso, para ilustrar as razões de querer ou não o parto cesáreo, permitindo respostas múltiplas.

A todas as mulheres entrevistadas foi explicado que seus dados seriam utilizados anonimamente numa pesquisa sobre assistência ao parto, com objetivo de melhorar a qualidade da atenção às mulheres, sendo facultada a todas a possibilidade de não participar da entrevista e assegurados a confidencialidade e o anonimato. A pesquisa foi aprovada pelo Comitê de Ética da Fiocruz e todas mulheres que aceitaram participar assinaram termo de consentimento, tendo sido seguidas as recomendações da legislação brasileira (Resolução no 196/ 96 do Conselho Nacional de Saúde - http:/ / www.consel ho.saude.gov.br/ docs/ Reso196. doc) e da legislação internacional - Declaração de Helsinki (1964, reformulada em 1975, 1983, 1989, 1996 e 2000 - http:/ / www.wma.net/ e/ policy/ 17-c_e.html).

\section{Resultados}

Não encontramos diferenças importantes entre as duas maternidades no que diz respeito às características sociais das mulheres nem entre os tipos de parto. Tratava-se de uma população com baixa escolaridade (a maioria tinha o ensino fundamental incompleto), baixo poder aquisitivo (cerca de $75 \%$ tinham renda per capita de até $R \$ 200,00$ por mês), sem trabalho remunerado (seja ele formal ou informal) e que residia com companheiro. A maioria das muIheres tinha entre 20 e 34 anos no momento da pesquisa.

Apesar das semelhanças, sabe-se que as maternidades têm características diferentes no que diz respeito ao perfil de risco das pacientes internadas. A maternidade pública dispõe de unidade neonatal, com leitos de Unidade de Tratamento Intensivo (UTI) e Unidade Intermediária (UI), constituindo, por isso, referência para pacientes de risco, com prematuridade em cerca de um quarto dos partos. A maternidade conveniada pode ser caracterizada como de baixo risco, tendo pequeno índice de prematuridade e de gestantes de risco. Ambas têm um grande volume de partos por mês e mais de 1.000 partos por ano cada uma.

Para caracterizar a preferência das mulheres pelo tipo de parto, utilizamos dados obtidos por meio das perguntas feitas às 909 muIheres entrevistadas nas duas maternidades, bem como pela análise das entrevistas semiestruturadas com as 24 mulheres que tinham experiência com os dois tipos de parto.

\section{As mulheres preferem cesárea?}

Quando perguntadas se queriam que seu parto fosse cesáreo, a maioria das entrevistadas $(75,6 \%)$ respondeu que não. Esse percentual variou, na maternidade pública, de $62,9 \%$ (nas mulheres que tiveram parto cesáreo) a $81,5 \%$ (nas que tiveram parto vaginal); na maternidade conveniada a resposta negativa variou de 74,2\% (parto cesáreo) a 83,7\% (parto vaginal). Nas duas maternidades, apenas 24 mulheres não relataram preferência quanto ao tipo de parto (Tabela 1).

As razões mais freqüentemente apresentadas pelas mulheres para não quererem o parto cesáreo foram: "recuperação mais difícil e lenta no parto cesáreo" (39,2\%) e "dor e sofrimento maior depois da cesárea" (26,8\%). Essas duas razões prevaleceram, também, quando analisamos os dados das duas maternidades separadamente e por tipo de parto (Tabela 2 ).

Em terceiro lugar encontra-se um conjunto de respostas que categorizamos como "cultura do parto vaginal", correspondente a $23,9 \%$ das respostas. Dentro dessa categoria foram incluídas as respostas que afirmam o desejo por um parto normal, embora a razão nem sempre fosse clara: parto normal é melhor para mãe e para criança; sem justificativa; não sabia por que, apenas uma opinião; normal é natural, cesárea é artificial; parto vaginal é mais rápido; justificativa contraditória, dúvida, mas afirma que parto vaginal é melhor; a partir da experiência de outra pessoa; queria viver a experiência do parto normal (Tabela 2).

As mesmas duas categorias de respostas mais freqüentes também se destacaram nas entrevistas semi-estruturadas realizadas com a subamostra que experimentara ambos os tipos 
Tabela 1

Preferência das mulheres por tipo de parto, segundo a maternidade e o tipo de parto atual.

\begin{tabular}{|c|c|c|c|c|c|c|c|c|c|}
\hline \multirow[t]{3}{*}{ Queria parto cesáreo } & \multicolumn{4}{|c|}{ Pública } & \multicolumn{4}{|c|}{ Conveniada } & \multirow[t]{3}{*}{ Total } \\
\hline & \multicolumn{2}{|c|}{ Vaginal } & \multicolumn{2}{|c|}{ Cesáreo } & \multicolumn{2}{|c|}{ Vaginal } & \multicolumn{2}{|c|}{ Cesáreo } & \\
\hline & $\mathrm{n}$ & $\%$ & $\mathrm{n}$ & $\%$ & $\mathrm{n}$ & $\%$ & $n$ & $\%$ & \\
\hline Sim & 42 & 18,5 & 83 & 37,1 & 36 & 16,3 & 55 & 25,8 & 216 \\
\hline Não & 185 & 81,5 & 141 & 62,9 & 186 & 83,7 & 157 & 74,2 & 669 \\
\hline Total & 227 & 100,0 & 224 & 100,0 & 222 & 100,0 & 212 & 100,0 & 885 \\
\hline Sem preferência & 3 & & 7 & & 2 & & 12 & & 24 \\
\hline
\end{tabular}

Tabela 2

Razões apresentadas pelas mulheres que não queriam parto cesáreo, segundo a maternidade e o tipo de parto atual.

\begin{tabular}{|c|c|c|c|c|c|c|c|c|c|c|}
\hline \multirow[t]{3}{*}{ Razões } & \multicolumn{4}{|c|}{ Pública } & \multicolumn{4}{|c|}{ Conveniada } & \multicolumn{2}{|c|}{ Total } \\
\hline & \multicolumn{2}{|c|}{ Vaginal } & \multicolumn{2}{|c|}{ Cesáreo } & \multicolumn{2}{|c|}{ Vaginal } & \multicolumn{2}{|c|}{ Cesáreo } & \multirow[b]{2}{*}{$n$} & \multirow[b]{2}{*}{$\%$} \\
\hline & $\mathrm{n}$ & $\%$ & $n$ & $\%$ & $n$ & $\%$ & $n$ & $\%$ & & \\
\hline $\begin{array}{l}\text { Recuperação mais difícil } \\
\text { e lenta da cesárea }\end{array}$ & 69 & 37,3 & 50 & 35,5 & 75 & 40,3 & 68 & 43,3 & 262 & 39,2 \\
\hline $\begin{array}{l}\text { Dor, sofrimento maior } \\
\text { depois da cesárea }\end{array}$ & 44 & 23,8 & 46 & 32,6 & 42 & 22,6 & 47 & 29,9 & 179 & 26,8 \\
\hline "Cultura do parto vaginal" & 44 & 23,8 & 38 & 27,0 & 49 & 26,3 & 29 & 18,5 & 160 & 23,9 \\
\hline $\begin{array}{l}\text { Risco cirúrgico, medo da } \\
\text { anestesia, do corte, da infecção }\end{array}$ & 21 & 11,4 & 6 & 4,3 & 16 & 8,6 & 10 & 6,4 & 53 & 7,9 \\
\hline $\begin{array}{l}\text { Experiência anterior com } \\
\text { cesárea ou parto vaginal }\end{array}$ & 7 & 3,8 & 1 & 0,7 & 4 & 2,2 & 3 & 1,9 & 15 & 2,2 \\
\hline Total & 185 & 100,0 & 141 & 100,0 & 186 & 100,0 & 157 & 100,0 & 669 & 100,0 \\
\hline
\end{tabular}

de parto. Transcrevemos a seguir a resposta de algumas dessas mulheres, apontando as desvantagens da cesárea:

“Todas. Não vi meu filho, não peguei meu fiIho, não botei ele no peito, fiquei mais de 20 dias pra poder andar direito, muita dor nas costas, muita dor na minha coluna, horrível. Para mim todas as desvantagens, não gostei de nada. Eu acho que a cesariana só devia ser opção mesmo em caso de vida ou morte. Eu acho que todas as mulheres deviam se conscientizar de que o parto normal é o mel hor" (C., 29 anos, três partos vaginais, um cesáreo e um vaginal).

“(...) No normal, no outro dia você já está andando, conversando, enesse a gente não pode nem conversar muito" ( V., 35 anos, um parto vaginal e um cesáreo).

E quais seriam as razões apontadas pelas mulheres que gostariam que o seu parto fosse cesáreo? Nesses casos, que representam $24,4 \%$ do total das entrevistadas, destaca-se a "dor e o sofrimento menor durante o trabalho de par- to" $(29,2 \%)$ e o "desejo de laqueadura" $(24,1 \%)$. Aparecem também como categorias importantes a "condição de saúde da mulher" (13,4\%); o "medo" (8,3\%); e o "passado obstétrico da muIher" (8,3\%). Categorizamos como "cultura do parto cesáreo" $11,1 \%$ das respostas, que afirmavam esta preferência embora a razão nem sempre estivesse clara: sem explicação, não sabe por que; por curiosidade; "riscos" do parto normal não especificados; justificativa contraditória, dúvida, mas prefere cesárea; cesárea mais rápida; a partir da experiência ou opinião dos outros (Tabela 3).

É interessante notar que a preocupação com danos ao períneo ou efeitos negativos na vida sexual, sugerida pelos profissionais como razão para as mulheres desejarem o parto cesáreo, não figura entre as razões dadas pelas muIheres entrevistadas neste estudo.

As duas primeiras categorias de razões se mantêm importantes nas duas maternidades, embora com maior destaque para as mulheres 
Razões apresentadas pelas mulheres que queriam parto cesáreo segundo, a maternidade e o tipo de parto atual.

\begin{tabular}{|c|c|c|c|c|c|c|c|c|c|c|}
\hline \multirow[t]{3}{*}{ Razões } & \multicolumn{4}{|c|}{ Pública } & \multicolumn{4}{|c|}{ Conveniada } & \multicolumn{2}{|c|}{ Total } \\
\hline & \multicolumn{2}{|c|}{ Vaginal } & \multicolumn{2}{|c|}{ Cesáreo } & \multicolumn{2}{|c|}{ Vaginal } & \multicolumn{2}{|c|}{ Cesáreo } & \multirow[b]{2}{*}{$n$} & \multirow[b]{2}{*}{$\%$} \\
\hline & $\mathrm{n}$ & $\%$ & $\mathrm{n}$ & $\%$ & $\mathrm{n}$ & $\%$ & $\mathrm{n}$ & $\%$ & & \\
\hline Dor e sofrimento menores & 14 & 33,3 & 19 & 22,9 & 14 & 38,9 & 16 & 29,1 & 63 & 29,2 \\
\hline Desejo de laqueadura & 13 & 31,0 & 17 & 20,5 & 14 & 38,9 & 8 & 14,5 & 52 & 24,1 \\
\hline Condições de saúde da mulher & 4 & 9,5 & 12 & 14,5 & 3 & 8,3 & 10 & 18,2 & 29 & 13,4 \\
\hline "Cultura da cesárea" & 5 & 11,9 & 8 & 9,6 & 2 & 5,6 & 9 & 16,4 & 24 & 11,1 \\
\hline $\begin{array}{l}\text { Medo, medo de complicação, } \\
\text { nervoso }\end{array}$ & 3 & 7,1 & 9 & 10,8 & 0 & 0,0 & 6 & 10,9 & 18 & 8,3 \\
\hline $\begin{array}{l}\text { Experiência anterior com } \\
\text { cesárea, passado obstétrico }\end{array}$ & 0 & 0,0 & 14 & 16,9 & 0 & 0,0 & 4 & 7,3 & 18 & 8,3 \\
\hline Condições de saúde da criança & 1 & 2,4 & 4 & 4,8 & 2 & 5,6 & 0 & 0,0 & 7 & 3,2 \\
\hline Recuperação melhor & 2 & 4,8 & 0 & 0,0 & 1 & 2,8 & 2 & 3,6 & 5 & 2,3 \\
\hline Total & 42 & 100,0 & 83 & 100,0 & 36 & 100,0 & 55 & 100,0 & 216 & 100,0 \\
\hline
\end{tabular}

que tiveram parto vaginal. As outras razões/ motivações apontadas pelas mulheres apresentaram distribuições que variaram entre as maternidades e os dois tipos de parto (Tabela 3).

$\mathrm{Na}$ análise das entrevistas semi-estruturadas, a grande vantagem atribuída ao parto cesáreo é não sentir as dores no momento do parto vaginal:

“Eu também não acho vantagem, mas a diferença é essa, vocênão sentea dor do parto" ( J . 32 anos, um parto vaginal e um cesáreo).

"Não tem a dor na hora, mas depois as dores vêm dobrado" (L., 25 anos, três partos vaginais e dois cesáreos).

"Só porque a gente não sente essas dores todas pra ter a criança normal. Eles dão logo aquela anestesia e el es rapi dinho tiram a criança. A gente só vai sentir depois a dor, ardendo..." (R., 25 anos, um parto vaginal e um cesáreo).

O desejo por cesárea parece ter sido influenciado pela experiência anterior de parto da mulher. Entre as 227 mulheres que já haviam experimentado pelo menos uma cesárea, independentemente do tipo de parto atual e da maternidade, o desejo pelo parto cesáreo foi em média duas vezes mais freqüente, em comparação às mulheres que nunca fizeram cesárea.

No grupo com cesárea anterior, as razões apontadas com mais freqüência para querer o parto cesáreo foram "dor, sofrimento menor" (21,9\%), "desejo de laqueadura" $(21,9 \%)$ e, logo em seguida, "experiência anterior com cesárea, passado obstétrico" (16,2\%). A última razão sugere a hipótese de que essas mulheres já tenham absorvido a "cultura" médica de "uma vez cesárea, sempre cesárea".
Em resposta à pergunta “Atualmente, muitas mulheres fazem cesárea. Por que você acha que isso vem acontecendo?", a maioria das 24 mulheres entrevistadas na subamostra apontou as dores, o medo, a falta de informação com relação ao desenvolvimento do parto normal e o desejo de laqueadura como motivos para outras mulheres pedirem cesárea.

“Porque eu acho que tem muita mulher que não gosta de sentir dor, só que éilusão, porque a dor do parto é só aquela hora, mas a cesárea vai ficar di reto, a dor do parto você sente e com uma semana você já está normal. Agora, a cesárea não, ela fica ali, ela incomoda, fica aquela cólica por dentro, tem que vir pra tirar ponto..." (A., 26 anos, dois partos vaginais e um cesáreo).

“Acho loucura. Medo, falta de informação, principalmente falta de informação. E medo só pode, porque uma pessoa querer fazer uma cesárea é uma loucura, além de você ficar com aquel e corte na barriga, depois também vocêfica toda ruim" (M., 39 anos, um parto cesáreo e um vaginal).

“Medo da dor e querer ligar. (...) Eu, como passei por essas, se fosse ter outro filho agora eu não queria assim de novo não, não queria cesárea não, faria tudo pra reverter para um normal" (J., 22 anos, um parto vaginal e um cesáreo).

"Porque tem muitas que não querem sofrer, não querem senti r. Antes dos nove meses pedem logo para fazer cesárea, porque não querem sentir dor" (L., 27 anos, um parto cesáreo e um vaginal)

“Ah, sei lá. Besteira. Uma cirurgia é sempre uma cirurgia, não deve se mexer tanto dentro 
da gente como na cesárea. Ah, pedem por causa disso, porque quando começa a dor da contração fica estranho pra caramba" (C., 27 anos, um parto cesáreo e um vaginal).

N essas entrevistas, as mulheres que viveram a experiência dos dois tipos de parto relataram que as informações fornecidas sobre o motivo da realização de cesárea foram insuficientes, deixando-as com muitas dúvidas, o que contribuiu para aumentar a ansiedade do momento. Além disso, relataram também o fato de não terem sido informadas sobre os riscos e as dificuldades para se recuperar da cirurgia.

Entre as mulheres que tinham acabado de ter o primeiro filho, observamos um percentual ligeiramente maior de desejo de parto vaginal, o que reforça a idéia de uma cultura feminina de parto vaginal. Apesar disto, o pedido de cesárea foi discretamente maior entre as parturientes de primeira vez. Podemos, portanto, indagar se as condições no pré-parto e durante o parto levaram as mulheres a solicitar a cesárea, mesmo sem desejá-la a princípio.

Entre as mulheres que relataram o desejo por cesárea, a principal razão das que tinham pelo menos um filho foi o "desejo de laqueadura"; já nas puérperas que haviam acabado de ter o primeiro filho, destaca-se "dor, sofrimento menor".

\section{As mulheres pediram cesárea?}

A maioria absoluta das mulheres (82,9\%) informou que não pediu para fazer cesárea, tanto aquelas que tiveram parto vaginal (81\%) como as que foram submetidas ao parto operatório (85\%).

Isso sugere, em primeiro lugar, que a maioria dos partos cesáreos não foi feita "a pedido". A maioria das mulheres que sofreram cesárea não o solicitaram. Ao mesmo tempo, 19\% das que tiveram parto vaginal reportaram que haviam pedido cesárea. Isso revela o poder limitado das mulheres em determinar o tipo de parto que vão fazer, seja ele vaginal ou cesárea, nas maternidades estudadas.

Das mulheres que solicitaram a cesárea, a maioria absoluta $(77,8 \%)$ o fez durante o trabaIho de parto e/ ou parto, tendo essa proporção variado de $89 \%$ nas mulheres que tiveram parto vaginal a $65 \%$ nas que tiveram cesárea ( $T a-$ bela 4). Ainda mais revelador é o fato de que, entre as mulheres que não queriam cesárea, mas que por algum motivo a solicitaram, a maioria absoluta $(93,9 \%)$ o fez durante o trabaIho de parto e/ ou parto. Esse fato parece confirmar a opinião das entrevistadas, que enfatizam que o pedido decorre da dor do parto.
O percentual de mulheres que pediram para fazer cesárea durante o pré-natal foi maior entre as que efetivamente foram submetidas à cesárea, o que sugere que, nesses casos, a cesárea pode ter sido acordada previamente a qualquer ocorrência relacionada ao parto, seja por uma real situação de saúde da paciente, seja por interesse na real ização de laqueadura (Tabela 4).

Observamos também que, quanto maior o intervalo de tempo entre a admissão da mulher no hospital e o parto, mais freqüente a solicitação de cesárea. Do mesmo modo, o tempo entre a admissão e o parto reflete ainda o momento em que se dá o pedido pelo parto cesáreo, ou seja, para aquelas mulheres para as quais o intervalo foi maior, o pedido ocorreu no momento do trabalho de parto e/ ou parto, enquanto para as que ficaram menos tempo o maior percentual de pedidos deu-se durante o pré-natal (Figura 1).

Embora o número de laqueaduras tubárias realizadas nessa amostra não tenha sido expressivo (na maternidade pública, 3,0\% dos partos vaginais e $9,6 \%$ dos partos cesáreos; na maternidade conveniada, $0,4 \%$ dos partos vaginais e $6,7 \%$ dos partos cesáreos), percebemos haver uma relação entre laqueadura e parto cesáreo.

\section{Discussão e conclusões}

Os dados aqui apresentados demonstram que a maioria das mulheres pesquisadas não queria ter um parto cesáreo, o que contrasta com a noção de valorização cultural que tem sido afirmada por obstetras em estudos brasileiros como os já referidos anteriormente. Mesmo quando o pedem, as mulheres não afirmam sua superioridade, apresentando motivos mais complexos e mais concretos do que os que têm sido relatados pelos médicos.

As circunstâncias que cercam a assistência no momento do pré parto/parto, incluindo a ausência de um acompanhante no momento do parto (fato que ocorreu em quase todos os casos), o tempo entre a admissão e o parto, e a experiência anterior de parto, foram fatores relacionados com o pedido de parto cesáreo. 0 não uso rotineiro de técnicas de alívio da dor, farmacológicas ou não, durante o pré-parto e o parto pode, de modo especial, ter também grande peso na construção do pedido da mulher por um parto cesáreo.

A OMS, no documento "Assistência ao parto normal: um guia prático", sugere uma série de práticas úteis que devem ser estimuladas, 
Distribuição das mulheres que pediram para fazer cesárea nas duas maternidades, segundo o momento do pedido e o tipo de parto.

\begin{tabular}{|c|c|c|c|c|c|c|c|c|c|c|}
\hline \multirow{3}{*}{$\begin{array}{l}\text { Momento em que } \\
\text { pediu cesárea }\end{array}$} & \multicolumn{4}{|c|}{ Pública } & \multicolumn{4}{|c|}{ Conveniada } & \multicolumn{2}{|c|}{ Total } \\
\hline & \multicolumn{2}{|c|}{ Vaginal } & \multicolumn{2}{|c|}{ Cesáreo } & \multicolumn{2}{|c|}{ Vaginal } & \multicolumn{2}{|c|}{ Cesáreo } & \multicolumn{2}{|c|}{ Tolai } \\
\hline & $\mathrm{n}$ & $\%$ & $\mathrm{n}$ & $\%$ & $\mathrm{n}$ & $\%$ & $\mathrm{n}$ & $\%$ & $\mathrm{n}$ & $\%$ \\
\hline Pré-natal & 1 & 3,6 & 12 & 32,4 & 5 & 8,8 & 7 & 22,6 & 25 & 16,3 \\
\hline Admissão & 2 & 7,1 & 0 & 0,0 & 3 & 5,3 & 4 & 12,9 & 9 & 5,9 \\
\hline Trabalho de parto e/ou parto & 25 & 89,3 & 25 & 67,6 & 49 & 86,0 & 20 & 64,5 & 119 & 77,8 \\
\hline Total & 28 & 100,0 & 37 & 100,0 & 57 & 100,0 & 31 & 100,0 & 153 & 100,0 \\
\hline
\end{tabular}

Figura 1

Distribuição das mulheres segundo o momento do pedido de cesárea e o tempo entre a admissão e o parto.

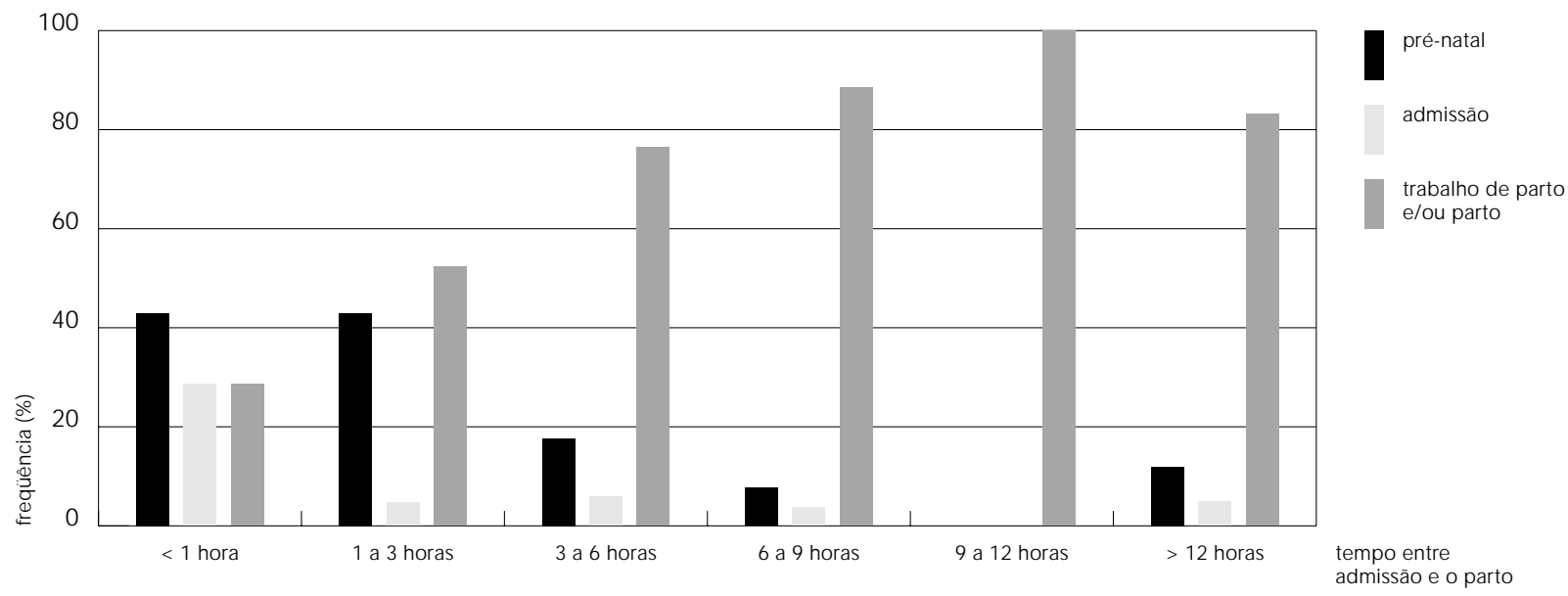

ao mesmo tempo que desaconselha outras. Entre as recomendadas, gostaríamos de destacar: respeito à escolha da mulher por um acompanhante de sua preferência durante o trabalho de parto e parto; fornecimento das formações e explicações solicitadas; uso de métodos não farmacológicos e não invasivos de alívio da dor, tais como massagens e técnicas de relaxamento; e liberdade de posição e movimentação durante o trabalho de parto (OMS, 1996). O Ministério da Saúde (MS, 2001) aponta também para a necessidade de mudança na assistência à mulher no pré-natal e no nascimento, estimulando procedimentos pouco invasivos que envolvam sua participação ativa. No entanto, tais práticas não são rotineiramente observadas.
Com relação ao desejo de laqueadura - uma das principais razões para a solicitação de parto cesáreo -, acreditamos que só com um programa de planejamento familiar efetivo, com o oferecimento e o acesso a todos os métodos contraceptivos, bem como a implantação real das já mencionadas leis e portarias de planejamento familiar existentes no Brasil, é que se conseguirá quebrar a associação nociva "cesárea - laqueadura".

U ma "cultura da cesárea”, que considera esse tipo de parto a melhor forma de nascer, parece ainda não estar totalmente introjetada nas mulheres. A justificativa da "cesárea a pedido da mulher", muitas vezes relatada pelos profissionais de saúde, parece refletir mais uma cul- 
tura médica do que uma real preferência das parturientes. Entretanto, deve-se levar em conta que o estudo foi realizado em apenas duas maternidades, uma pública e outra conveniada, não tendo sido estudada nenhuma maternidade do setor privado. Um estudo que incluísse outras maternidades poderia mostrar diferenças na incorporação de uma suposta "cultura da cesárea".

\section{Agradecimentos}

Agradecemos à Fundação Ford e ao Consel ho Nacional de Desenvolvimento Científico e Tecnológico o apoio dado a esta pesquisa.

\section{Referências}

ÁVILA, M. B., 1993. Modernidade e cidadania reprodutiva. Estudos Feministas, 1:382-393

BEMFAM (Sociedade Civil Bem-Estar Familiar no Brasil), 1997. Pesquisa Nacional de Demografia e Saúde, 1996. Rio de Janeiro: BEM FAM.

BERQUÓ, E.,1999. Ainda a questão da esterilização feminina. In: Questões de Saúde Reprodutiva (K. Giffin \& S. H. Costa, org.), pp. 113-126, Rio de Janeiro: Editora Fiocruz

BRENES, A. C., 1991. História da parturição no Brasil, Século XIX. Cadernos de Saúde Pública 7:135-149.

CAM POS, T. P. \& CARVALHO, M. S., 2000. Assistência ao parto no município do Rio de Janeiro: Perfil das maternidades e o acesso da clientela. Cadernos de Saúde Pública, 16:411-420.

DINIZ, C. S. G., 1996. Assistência ao Parto e Relações de Gênero: Elementos para uma Rel eitura MédicoSocial. Dissertação de M estrado, São Paulo: Faculdade de Medicina, Universidade de São Paulo.

FAUNDES, A. \& CECATTI, J. G., 1991. A operação cesárea no Brasil. Incidência, tendências, causas, conseqüências e propostas de ação. Cadernos de Saúde Pública, 7:150-173.

GIFFIN, K., 1991. Nosso corpo nos pertence: A dialética do biológico e do social. Cadernos de Saúde Pública, 7:190-200.

HOPKINS, K., 2000. Are Brazilian women really choosing to deliver by cesarean? Social Science and Medicine, 51:725-740.

M CCLAIN, C., 1990. The making of a medical tradition: vaginal birth after cesarean. Social Science and Medicine, 31:203-210.

MELLO-E-SOUZA, C., 1994. C-sections as ideal births: The cultural construction of beneficence and patents' rights in Brazil. Cambridge Quartely Health Care Ethics, 3:358-366.

MILLER, J. M., 1988. Maternal and neonatal morbidity and mortality in cesarean section. Obstetrics and Gynecology Clinics of North America, 15:629-638.

MS (Ministério da Saúde), 2001. Parto, Aborto e Puerpério: Assi stência Humanizada à Mulher. Brasília: MS.

NÚ CLEO DE ESTUDOS DE POPULAÇÃO, 1996. Pesqui sa sobre Saúde Reprodutiva e Práticas Obsté-
Concluímos que devemos continuar a desmistificar essa idéia e investir na melhoria da atenção durante pré-natal, pré-parto e parto, para que a mulher se sinta apoiada e conheça melhor o que ocorre com ela durante a gravidez e o parto, diminuindo assim seus medos e inseguranças e colocando-a como agente principal de um momento ímpar na sua vida, o nascimento de um filho. tricas no Brasil. Campinas: Núcleo de Estudos de População, Universidade Estadual de Campinas.

OMS (Organização Mundial da Saúde), 1996. Assistência ao Parto Normal: U m Guia Prático. Genebra: OMS.

POTTER, J. E.; BERQUÓ, E.; PERPÉTUO, I. H. O.; LEAL, O. F.; HOPKINS, K.; SOUZA, M. R. \& FORMIGA, M. C. C., 2001. Unwanted cesarean sections among public and private patients in Brazil: Prospective study. BMJ, 323:1155-1158.

RATNNER, D., 1996. Sobre a hipótese de estabilização das taxas de cesárea do Estado de São Paulo. Revista de Saúde Pública, 30:19-33.

SAKALA, C., 1993. Medically unnecessary cesarean section births: Introduction to a symposium. Social Science and Medicine, 37:1177-1198.

SCAVONE, L., 1992. O impacto das tecnologias médicas na família. In: XVI Encontro Anual da Associação Nacional de Pós-graduação em Ciências Sociais - ANPOCS, Anais, pp. 20-23, Caxambu: ANPOCS. (mimeo.)

SHEARER, E., 1993. Cesarean section: Medical benefits and costs. Social Science and Medicine, 37:12231231.

SILVER, L. D., 1999. Direito à saúde ou medicalização da mulher? Implicações para avaliação dos serviços de saúde para as mulheres. In: Questões de Saúde Reprodutiva (K. Giffin \& S. H. Costa, org.), pp. 299-317, Rio de Janeiro: Editora Fiocruz.

VALLADARES, D. P., 1999. As ações de contracepção e assistência ao parto: A experiência do Rio de Janeiro. In: Questões de Saúde Reprodutiva (K. Giffin \& S. H. Costa, org.), pp. 357-376, Rio de Janeiro: Editora Fiocruz.

VIEIRA, E. M., 1999. A medicalização do corpo feminino. In: Questões de Saúde Reprodutiva (K. Giffin \& S. H. Costa, org.), pp. 67-78, Rio de Janeiro: Editora Fiocruz.

Recebido em 20 de junho de 2002

Versão final reapresentada em 18 de dezembro de 2002 Aprovado em XX de XX de 2003 